\title{
EFEK MEDIASI KESADARAN MEREK PADA PENGARUH TANGGUNG JAWAB SOSIAL PERUSAHAAN TERHADAP MINAT NASABAH MENGGUNAKAN PRODUK BANK CENTRAL ASIA (BCA) DI JAKARTA
}

\author{
Anthaony Ryann Welington \\ Program Studi Magister Manajemen Universitas Tarumanagara \\ anthaony.117172056@stu.untar.ac.id
}

\begin{abstract}
This research aims to determine the role of brand awareness in mediating the effect between corporate social responsibility (CSR) towards purchase intention. The method used is a quantitative method with the type of research is descriptive. In this research, there are 3 variables : brand awareness, corporate social responsibility, and purchase intention. Sampling method used is purposive non-probability sampling with 129 respondents. The analysis technique used is mediation analysis. This research found that brand awareness as mediating variable significantly affect the relationship between corporate social responsibility (CSR) and purchase intention. Corporate social responsibility (CSR) through brand awareness have positive and significant influence simultaneously towards buying intention by $44.6 \%$, and the rest $55.4 \%$ is influenced by other variables not examined in this research.
\end{abstract}

\begin{abstract}
Abstrak : Penelitian ini bertujuan untuk mengetahui peran Kesadaran Merek dalam memediasi pengaruh Tanggung Jawab Sosial terhadap Minat Nasabah. Metode yang digunakan adalah metode kuantitatif dengan jenis penelitian deskriptif. Pengambilan sampel menggunakan metode non-probability sampling jenis purposive sampling dengan 129 responden. Teknik analisis data menggunakan analisis Mediasi. Penelitian ini menemukan bahwa Tanggung Jawab Sosial melalui Kesadaran Merek mempunyai kontribusi dalam menjelaskan variasi dari Minat Nasabah sebesar $44.6 \%$ sedangkan sisanya sebesar $55.4 \%$ dijelaskan oleh variabel lain yang tidak diperhitungkan dalam model.
\end{abstract}

Keywords : Corporate Social Responsibility, Brand Awareness, Purchase Intention

\section{PENDAHULUAN}

Persaingan di dalam sektor perbankan sangat ketat di mana industri perbankan mengandalkan nasabah yang dimiliki oleh masing-masing bank. Maka dari itu, sangatlah penting bagi sebuah bank untuk mendapatkan dan mempertahankan nasabah yang berkualitas demi kelangsungan hidup usaha bank tersebut. Lembaga Penjamin Simpanan (LPS) menyatakan bahwa pertumbuhan kredit perbankan nasional pada tahun 2017 khususny September 2017 yaitu sebesar 7,9\% lebih rendah dibandingkan periode Agustus 2017 yaitu sebesar 8,3\%. Ketua Dewan Komisioner LPS, Halim Alamsyah menjelaskan memang dalam dua tahun terakhir risiko kredit mengalami penurunan, sehingga perbankan perlu efektif dan efisien dalam menjalankan operasional serta mengembangkan strategi untuk meningkatkan profitabilitasnya. Sebaliknya BCA dan entitas anak perusahaannya melaporkan kinerja keuangan konsolidasi sepanjang sembilan bulan pertama yang berakhir pada 30 September 2017. Laba bersih meningkat 11,3\% menjadi Rp 16,8 triliun dari Rp 15,1 triliun pada periode yang sama tahun sebelumnya (2016). Pendapatan operasional yang terdiri dari pendapatan bunga bersih dan pendapatan operasional lainnya tumbuh 5,2\% menjadi Rp 41,7 triliun pada sembilan bulan pertama tahun 2017, dibandingkan Rp 39,7 triliun pada sembilan bulan pertama tahun 2016 (BCA, 2017).

Dengan posisi BCA yang kokoh dan bisnis perbankan, BCA terus mengembangkan srateginya untuk meningkatkan minat nasabah agar dapat mempertahankan posisinya. Melalui pemahaman perilaku konsumen, pihak manajemen perusahaan dapat menyusun strategi yang 
efektif dan efisien dalam rangka memanfaatkan peluang yang ada dan mengungguli para pesaingnya. Ajzen dan Fishbein (1980) menegaskan dalam "theory of reasoned action" bahwa perilaku konsumen dapat diprediksikan lewat intensi mereka melalui tindakan, tujuan, dan konteks perilaku mereka, sehingga pengukuran minat nasabah akan lebih efektif daripada pengukuran perilaku untuk memprediksi apakah konsumen akan melakukan pembelian. Faktor-faktor yang mempengaruhi minat nasabah pada industri perbankan antara lain Corporate Social Responsibility (Polychronidou, et al. (2014) dan Brand awareness (Romaniuk et al, 2004). Penelitian ini bertujuan untuk menguji efek Mediasi Kesadaran Merek pada pengaruh Tanggung Jawab Sosial (CSR) terhadap Minat Nasabah menggunakan produk Bank Central Asia (BCA) di Jakarta.

\section{TINJAUAN PUSTAKA}

CSR (Tanggung Jawab Sosial Perusahaan) adalah bisnis yang dilakukan secara transparan dan terbuka yang memiliki kepentingan untuk meningkatkan kesejahteraan masyarakat melalui tindakan bebas dan kontribusi sumber daya perusahaan. Kesadaran Merek merupakan kemampuan sebuah merek untuk muncul dalam benak konsumen ketika mereka sedang memikirkan kategori produk tertentu dan seberapa mudahnya nama tersebut dimunculkan dan mengungkapkan bahwa perusahaan yang konsisten melakukan CSR dapat meningkatkan brand awareness pada masyarakat (Shimp,2010).

$\mathrm{H}_{1}$ : Terdapat pengaruh positif corporate social responsibility $(C S R)$ terhadap brand awareness nasabah Bank Central Asia di Jakarta.

Minat beli dapat diartikan sebagai bagian dari komponen perilaku konsumen melalui rencana konsumen dengan kencenderungan konsumen untuk membeli suatu produk atau jasa dalam mengambil tindakan sebelum keputusan membeli benar-benar dilaksanakan pada masa yang akan datang. Penerapan CSR memiliki beberapa manfaat bagi perusahaan yang salah satunya mendapatkan Social Licence to Corporate. Masyarakat sekitar perusahaan merupakan komunitas utama perusahaan. Ketika mereka mendapatkan manfaat dari keberadaan perusahaan, mereka ikut merasa memiliki perusahaan, sehingga imbalan yang diberikan kepada perusahaan paling tidak adalah keleluasaan perusahaan untuk menjalankan roda bisnisnya di wilayah tersebut. Jadi program Corporate Sosial Responsibility (CSR) diharapkan menjadi bagian dari asuransi sosial (social insurance) yang akan menghasilkan harmoni dan persepsi positif dari masyarakat terhadap minat menjadi bagian dari perusahaan dan pada akhirnya meningkatkan minat beli konsumen (Huang, et al. (2016).

$\mathrm{H} 2$ : Terdapat pengaruh positif corporate social responsibility (CSR) terhadap minat nasabah menggunakan produk Bank Central Asia di Jakarta

Pengetahuan terhadap kesadaran merek akan berpengaruh terhadap minat beli konsumen (Kwan, 2001). Konsumen akan cenderung membeli produk dengan merek yang sudah terkenal dibandingkan dengan produk yang mereknya masih asing ditelinga mereka. Minat beli juga didasarkan pada pengetahuan konsumen yang mereka peroleh dari media informasi mengenai merek produk tersebut. Lebih lanjut hasil penelitian Setyawan (2010) juga menyatakan bahwa semakin tinggi tingkat kesadaran merek seseorang, maka minat beli konsumen terhadap produk dengan merek tersebut meningkat karena merek itulah yang pertama diingatnya.

H3 : Terdapat pengaruh positif brand awareness terhadap minat nasabah menggunakan produk Bank Central Asia di Jakarta.

Dalam perkembangannya CSR menjadi sangat penting peranannya bagi perusahaan untuk memperkuat minat beli konsumen, dimana dalam hal ini menurut Kotler dan Lee (2005), CSR mampu memberikan banyak keuntungan bagi perusahaan yang telah melakukan. Jika pelaksanaan CSR baik dimata masyarakat, maka akan berdampak pada kesadaran merek yang tinggi terhadap Perusahaan. Selanjutnya Brand awareness akan terbentuk dengan adanya kegiatan CSR dari perusahaan dan dengan adanya brand awareness dari konsumen maka besar kemungkinan minat beli konsumen juga akan tercipta (Romaniuk, et al., 2004). Berdasarkan 
uraian di atas, dapat dikatakan bahwa corporate social responsibility (CSR) melalui brand awareness (kesadaran merek) mempunyai pengaruh terhadap minat nasabah (Sen \& Bhattacharya, 2004).

$\mathrm{H} 4$ : Brand awareness dapat memediasi pengaruh corporate social responsibility (CSR) terhadap minat nasabah menggunakan produk Bank Central Asia di Jakarta.

\section{METODE PENELITIAN}

Metode penelitian yang digunakan adalah penelitian kuantitatif-deskriptif. Ada tiga macam variabel yang digunakan dalam penelitian ini yaitu variabel bebas (corporate social responsibility), variable mediasi (brand awareness) dan variabel terikat (dalam hal ini adalah purchase intention). Populasi dalam penelitian ini adalah konsumen BCA yang berlokasi di wilayah DKI Jakarta. Teknik pengambilan sampel adalah Non Probability Sampling yaitu teknik convenience sampling, yaitu mengambil responden sebagai sampel berdasarkan kebetulan atau siapa saja yang kebetulan bertemu dengan peneliti. Jumlah sampel dalam penelitian ini adalah 129 responden.

Pernyataan untuk variabel bebas (corporate social responsibility), variable mediasi (brand awareness) dan variabel terikat (dalam hal ini adalah purchase intention) terdiri atas 13 item pernyataan. Uji validitas terhadap pernyataan-pernyataan tersebut menggunakan SPSS 23.00 dan semua butir valid karena memenuhi syarat memiliki corrected item-total correlation lebih besar dari 0,3. Hasil uji reliabilitas seluruh variabel memiliki nilai koefisien cronbach's alpha lebih dari 0,60 maka dapat disimpulkan bahwa semua butir pertanyaan reliabel.

\section{HASIL PENELITIAN}

Dari hasil analisa deskriptif, jumlah responden pria (53.5\%) lebih tinggi dibandingkan responden wanita (46.5\%). Selanjutnya usia 26-30 tahun merupakan responden dengan jumlah paling banyak yaitu sebesar $46(35.7 \%)$. Responden usia ini memiliki kecenderungan aktif untuk mencoba berbagai hal baru termasuk kegiatan CSR yang dilakukan oleh Bank. Responden dengan pekerjaan sebagai pegawai swasta juga memiliki jumlah tertinggi yaitu 89 (69\%), kemudian responden dengan latar belakang pendidikan S1/Sederajat juga paling tinggi dengan jumlah 68 (52.7\%) dan responden yang memiliki pengeluaran Rp 1.000.000,Rp5.000.000,- per bulan untuk berbelanja merupakan jumlah responden tertinggi dengan jumlah $50(38.8 \%)$. Kemudian untuk jumlah produk yang dimiliki, jumlah responden tertinggi dengan jumlah 70 responden $(54.3 \%)$ memiliki 1-2 produk, lalu untuk jangka waktu menjadi nasabah, jumlah responden tertinggi sebanyak 119 responden (92.2\%) menjawab sudah lebih dari 3 tahun menjadi nasabah, dan yang terakhir pada alasan menjadi nasabah BCA, responden jumlah paling banyak yaitu 61 responden (47.3\%) menjawab karena BCA merupakan perusahaan yang peduli pada lingkungan dan sosial.

\section{Analisis Mediasi}

\section{a. Uji Hipotesis}

Untuk menguji hipotesis utama penelitian ini, yaitu untuk melihat adanya efek mediasi Brand Awareness pada pengaruh Corporate Social Respobisility terhadap Purchase Intention, maka perlu dilakukan pengujian hipotesis-hipotesis yang lain terlebih dahulu.

Uji Hipotesis 1

Nilai p value sebesar 0.00, maka diputuskan untuk menolak Ho. Sehingga dapat disimpulkan bahwa terdapat pengaruh positif corporate social responsibility (CSR) terhadap brand awareness nasabah Bank Central Asia di Jakarta. Selain itu dapat juga disimpulkan bahwa salah satu tahap dari pengujian mediasi Baron \& Kenny diterima (tahap 2).

Uji Hipotesis 2

Nilai $p$ value sebesar 0.00 , maka diputuskan untuk menolak Ho. Sehingga dapat disimpulkan bahwa terdapat pengaruh positif corporate social responsibility (CSR) terhadap 
minat nasabah menggunakan produk Bank Central Asia di Jakarta. Selain itu dapat juga disimpulkan bahwa salah satu tahap dari pengujian mediasi Baron \& Kenny diterima (tahap 1). Uji Hipotesis 3

Nilai $p$ value variabel mediasi Brand Awareness pada pengaruh CSR terhadap variabel Purchase Intention adalah 0.000, yaitu lebih kecil dari 0.05 maka diputuskan untuk menolak Ho. Ini berarti bahwa terdapat pengaruh yang positif dan signifikan Brand Awareness terhadap Purchase Intention. Selain itu juga dapat disimpulkan bahwa salah satu tahap dari pengujian mediasi Baron \& Kenny diterima (tahap 3).

Uji Hipotesis 4

Nilai $p$ value variabel CSR terhadap variabel Purchase Intention setelah memasukan variabel mediasi Brand Awareness adalah 0.053, yaitu lebih besar dari 0.05. Ini berarti bahwa terdapat pengaruh yang positif namun tidak signifikan CSR terhadap Purchase Intention setelah memasukan mediasi Brand Awareness. Dapat dilihat bahwa pengaruh CSR terhadap minat beli yang sebelumnya positif dan signifikan tanpa adanya variabel mediasi brand awareness menjadi positif namun tidak signifikan, hal ini menunjukan bahwa brand awareness memediasi secara penuh pengaruh CSR terhadap minat beli, maka diputuskan untuk menolak Ho. Selain itu dapat juga disimpulkan bahwa salah satu tahap dari pengujian mediasi Baron \& Kenny diterima (tahap 4).

\section{b. Koefisien Determinasi}

Nilai R sebesar $44.5 \%$ dan nilai adjusted $\mathrm{R}$ square sebesar $44.6 \%$. Artinya variable $\mathrm{X}$ (Corporate Social Responsibility) melalui variable M (Brand Awareness) mempunyai kontribusi dalam menjelaskan variasi dari variabel Y (Purchase Intention) sebesar 44.6\% sedangkan sisanya sebesar $55.4 \%$ dijelaskan oleh variabel lain yang tidak diperhitungkan dalam model.

\section{SARAN}

Berdasarkan pada hasil penelitian yang telah dilakukan dapat dilihat bahwa perusahaan sebaiknya tidak hanya berorientasi pada profit saja namun juga harus memberikan kontribusi CSR (tanggung jawab social) bagi lingkungan dan para stakeholdernya, terbukti dengan adanya CSR yang baik dengan penyampaian yang efektif mampu memberikan pengaruh signifikan terhadap Purchase Intention (minat nasabah) pada produknya, khususnya produk BCA dalam penelitian ini. Purchase Intention (minat nasabah) merupakan poin penting dimana saat seorang konsumen memiliki niat untuk membeli produk atau jasa dari perusahaan banyak hal yang dapat memberikan pengaruh positif terhadap minat nasabah, baik Corporate Social Responsibility (CSR) maupun Brand Awareness. Maka perusahaan-perusahaan saat ini sebaiknya dapat menerapkan program CSR yang disampaikan kepada masyarakat secara efektif yang pada akhirnya dapat mendorong respon positif dari konsumen. Oleh karena itu cara untuk meningkatkan Brand Awareness melalui CSR perusahaan dapat dilakukan dengan lebih memberdayakan masyarakat sekitar dalam kegiatan perusahaan, memperluas ruang lingkup CSR, memberikan riterasi dan edukasi kepada masyarakat akan produk atau kegiatan pemerintah dalam bidang sosial dan pendidikan, serta memasukkan program CSR kedalam strategi promosi perusahaan. Akhir kata seperti yang diungkapkan sebelumnya bahwa banyak hal yang dapat memberikan pengaruh bagi Purchase Intention (Minat Nasabah), peneliti berharap penelitian ini dapat menjadi acuan bagi penelitian-penelitian selanjutnya serta dapat menjadi dasar pengembangan penelitian mediasi dalam ilmu Ekonomi khususnya bidang pemasaran di Indonesia. 


\section{DAFTAR PUSTAKA}

Amba-Rao, S.C. (1993). Multinational Corparate Social Responsibility, Ethics, Interactions, and Third World Government: An Agenda for the 1990s. Journal of Business Ethics, 12(7): 553-572

Amin, W. T. (2008). Memahami Economic Value Added. Jakarta: Harvando

Aritonang, L. R. (2002). Peramalan Bisnis. Jakarta: Ghalia Indonesia

Bhattacharya, C.B; Sankar, S; Daniel. K. (2007). Corporate Social Responsibility As An Internal Marketing Strategy. Forthcoming: Sloan Management Review

Biro Hubungan Masyarakat Bank Central Asia. (2017). PT Bank Central Asia Tbk Hasil Kinerja Sembilan Bulan Pertama 2017 - Mempertahankan Soliditas. Retrieved Maret 26, 2018, from BCA Web site : https://www.bca.co.id/id/TentangBCA/Korporasi/Siaran-Pers/2017/10/26/09/44/pt-bank-central-asia-tbk-hasil-kinerjasembilan-bulan-pertama-2017

Chang, M. K; Cheung, W; Cheng, C. H; and Yeung, J. H. Y. (2008). Understanding ERP system adoption from the user's perspective. International Journal of Production Economics, Vol. 113, No.2, pp.928-942

Chomvilailuk, R.; Butcher; Ken. (2013). The effect of CSR knowledge on customer liking, across cultures. The International Journal of Bank Marketing, 31 (2), 98-114

Currás-pérez; Rafael; Bigné-alcañiz; Enrique; Alvarado-herrera; Alejandro. (2009). The Role of Self-Definitional Principles in Consumer Identification with a Socially Responsible Company. Journal of Business Ethic, 89 (4), 547-564

Febrina, Sylke. (2017). Tantangan Perbankan Tahun Depan Kredit Lesu dan Serbuan Fintech. Retrieved April 18, 2019, from Detik Web site : https://finance.detik.com/moneter/d3737575/tantangan-perbankan-tahun-depan-kredit-lesu-dan-serbuan-fintech

Ghozali, I. (2005). Aplikasi Analisis Multivariate dengan program SPSS. Semarang: Badan Penerbit Universitas Diponegoro

He Hongwei; and Yan Li. (2011). Key service drivers for high-tech service brand equity: The mediating role of overall service quality and perceived value, Journal of Marketing Management, Vol. 27, No. 1-2, February 2011, pp. 77-99

Howard, A. (2004). Aljabar Linier Elementer. Edisi kedelapan. Jakarta: Penerbit Erlangga

Huang, Chun-Chen; Yen, Szu-Wei; Liu, Cheng-Yi; Huang, Pei-Chen. (2014). The Relationship among Corporate Social Responsibility, Service Quality, Corporate Image, and Purchase Intention. International Journal of Organizational Innovation (Online), 6 (3), 68-84

Khan. (2010). The effect of corporate governance elements on corporate social responsibility (CSR) reporting: Empirical evidence from private commercial banks of Bangladesh. International Journal of Law and Management. Vol.52. Hal. 82 - 109

Kotler, P.; and Nancy, L. (2005). Corporate Sosial Responsibility, Doing the Most Good for Your Company and Your Cause. John Wiley \& Sons Publisher

Kuncoro, M. (2007). Metode Kuantitatif, Teori dan Aplikasi untuk Bisnis dan Ekonomi, Yogyakarta: UPP STIM YKPN

Poolthong Y, Mandhachitara R. (2009). Customer expectations of CSR, perceived service quality and brand effect in Thai retail banking. International Journal of Bank Marketing. Vol.27. Hal. 408-427

Wibisono, Y. (2007). Membedah Konsep \& Aplikasi CSR (Corporate Social responsibility), Gresik : Fascho Publishing 